\title{
The Effect of the Combination of Various Training Methodologies in Horse Training on the Learning Performances of Arabian Horses
}

\author{
Sibel DANIŞAN ${ }^{1, *}$ (D), Ceyhan ÖZBEYAZ ${ }^{2}$ (D) \\ ${ }^{1}$ Eskişehir Osmangazi University, Mahmudiye Horse Breeding and Coaching Vocational School, Department of Plant \\ and Animal Production, Horse Breeding and Coaching Program, Eskişehir, Turkey. \\ ${ }^{2}$ Ankara University, Faculty of Veterinary Medicine, Department of Animal Husbandry, Ankara, Turkey.
}

\section{Article History}

Received: 19 May 2021

Accepted: 10 Aug 2021

First Online: 20 Sep 2021

\section{Corresponding Author}

E-mail: sibellsenturk@gmail.com

\section{Keywords}

Behavior

Horse

Training

Welfare

\begin{abstract}
This research aims at examining the learning performance of Arabian horses with the use of Join-up, Parelli's Seven Games, and Clicker methods in combination and separately. In the research, thirty-six Arabian mares were examined and combinations of training methods were applied. Before and after the application of each training method, horses were directed to pass through a narrow-spaces and to walk on a tarp While applying training methods, stress parameters, behavioral responses, and learning responses of horses were evaluated. The highest heart rates of the training groups were being during the application of the Join-up method. When the Parelli method was performed last, the training duration was $13.3 \%$ shorter. In walk on tarp task, the highest success score was in Clicker Method (75\%). In the triple combination of training, when the Join-up method was performed last, task success rates decreased (33.3\%). However, when the Join-up method was performed first, the success rate was $100 \%$. When Parelli's methods were applied last, conflict behaviors were prevented, all horses learned vocal cues, and trusted their trainers. During the application of the Clicker method, all horses learned vocal cues and trusted their trainers. It was concluded that the order of methods is so crucial.
\end{abstract}

\section{Introduction}

Horses, being herd animals in their nature, are isolated from other members of their species during the training, get into contact with humans, and be exposed to unfamiliar objects and stimuli (Parkin et al. 2018). This situation causes fear and anxiety in horses, and as a result, undesired behavior may occur. If obedience is due to oppression applied by the human, and not based on a reciprocal trust, the horse may feel insecure, and develop some instinctual behaviors such as escaping, resisting and fighting (Blanchard, 2005). Therefore, simple veterinary and animal husbandry interventions such as routine examinations and grooming can pose risks for human safety (Lansade et al. 2019). On the other hand, in all riding disciplines, appropriate methods improve the learning skills of horses, and decrease their undesired behaviors (McGreevy and McLean 2007). Although ensuring a high level of animal welfare is an important issue for contemporary animal husbandry, the development of optimal programs in the training of racehorses who started their sports career at a very young age cannot be achieved due to the lack of scientific knowledge on stress (Witkowska-Piłaszewicz et al. 2021). Though the physical exercise, if well organized, determines forms of adaptation that improve performance and "correct or optimal stress level" may have a positive impact on welfare (McEwen, 2019). Studies show that acute state-related behavioural patterns and horse's behaviour are used in the evaluation of horse welfare (Czycholl et al. 2018, Dalla Costa et al. 2016). The way to ensure the welfare of the horse and the safety of the people working with the horse is through understanding the factors that affect 
the horse's learning. Learning has been important for survival of equids during their evolutionary history changing their behaviors through experience and adapting to new environments and threats (Beaver, 2019). To minimize the risks associated with horse training, training methodologies must apply scientific knowledge on equine ethology, cognition, and learning (Fenner et al. 2019). Most of horse training methods are based on conventional practices, however these methods ignore the natural behaviors of horses. Therefore, in horse training, underlying processes beneath horse behaviors have to be comprehended (Waran et al. 2007). Waran and Randle (2017) stated that while scientific debates continue about the nature of consciousness, cognitive abilities and emotions that horses have compared to humans, it is important for horses to express their natural behavior in order to ensure the best quality of life. They also pointed out that keeping them away from poor training and management-related stresses is important for welfare.

\section{Conventional, Behavioral and Conspecific Horse Training}

The conspecific models typically explain the human-to-horse attachment through the application of the herd-leader premise (McGreevy et al. 2009). Conspecific models for instance Parelli's Seven Games and Join-up method focus on motivating the horse by the pressure-release (negative reinforcement) principle, using the horse's natural instincts or ethogram (Parelli 1993, Roberts 2000). This model implies that horses would innately respond to human interventions in the same way as they would when receiving analogous signals from conspecifics (Hartmann et al. 2017). The Behavioral training model maintains that horses are not culpable participants in training and that they learn through the correct timing application of positive and negative reinforcement schedules (McGreevy and McLean 2010). It is proposed that human attachment to horses is reliant on learning principles, such as the correct timing of positive and negative reinforcement, tactile rewards and praise as secondary reinforcers, and operant and classical conditioning processes. Kydd et al. (2017) drew attention to the importance of excellent timing when using negative reinforcement in horse training. The Conventional training model rests on a model of the benevolent/malevolent horse otherwise known as the "cooperative model" (McGreevy et al. 2009). There has been a recent tendency in horse training to not only incorporating positive reinforcement, but to completely eliminate the use of aversive stimuli in horse training (McLean and Christensen, 2017).

The aim of this study is to examine the learning performance of Arabian horses by applying Join-up, Parelli's Seven Games (Friendly Game, Porcupine Game) and Clicker methods together and separately.

\section{Materials and Methods}

\section{Ethical Statement}

This study was approved by the Ankara University Animal Ethics Committee (Approval no: 2015-05-91)

\section{Horses}

In the research, 36 Arabian mares in the General Directorate of Agricultural Enterprises (TIGEM) were used. Twelve one-year-old Arabian mares, twelve twoyear-old Arabian mares, and twelve Arabian mares over three years old were examined. Horses were routinely reared in a similar way. The horses studied did not show clinical symptoms of any illness nor show external symptoms of estrus. The experiment was conducted on the same stud farm where the horses had been raised.

\section{Equipment Used}

During each training test, horses were equipped with a Polar Equine M400 Heath Rate monitor. The monitors continuously recorded Heath Rate (HR). During each training tests, each horse was under constant video surveillance.

\section{Study Protocol}

Thirty-six Arabian mares are divided into six groups. All groups have six horses, two mares of each age group (Figure 1). All training applied to horses within the scope of the research was carried out by the researcher/trainer. The trainer, who was the first author
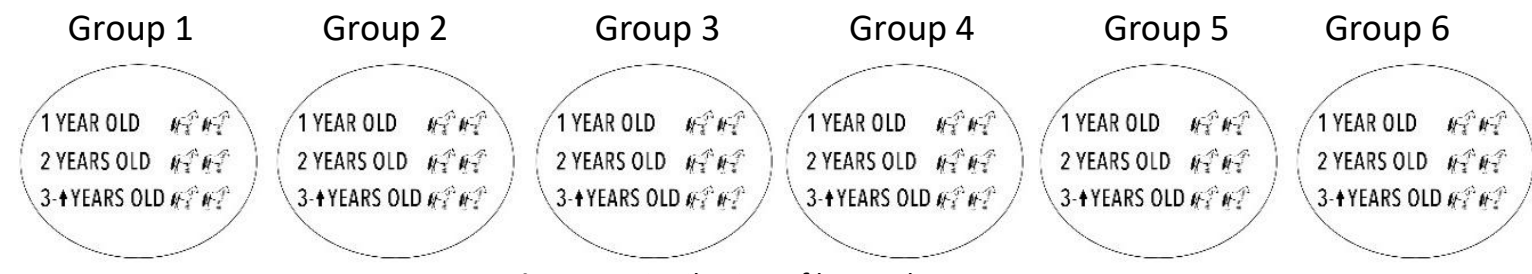

Figure 1. Distribution of horses by groups 
Table 1. The training methods and combinations

\begin{tabular}{llllll}
\hline Group 1 & Group 2 & Group 3 & Group 4 & Group 5 & Group 6 \\
\hline J* & J & P** & P & C*** & C \\
J-C & J-P & P-C & P-J & C-P & C-J \\
J-C-P & J-P-C & P-C-J & P-J-C & C-P-J & C-J-P \\
\hline
\end{tabular}

*Join-up Method, **Parelli's Games (Friendly Game, Porcupine Game), ***Clicker Method

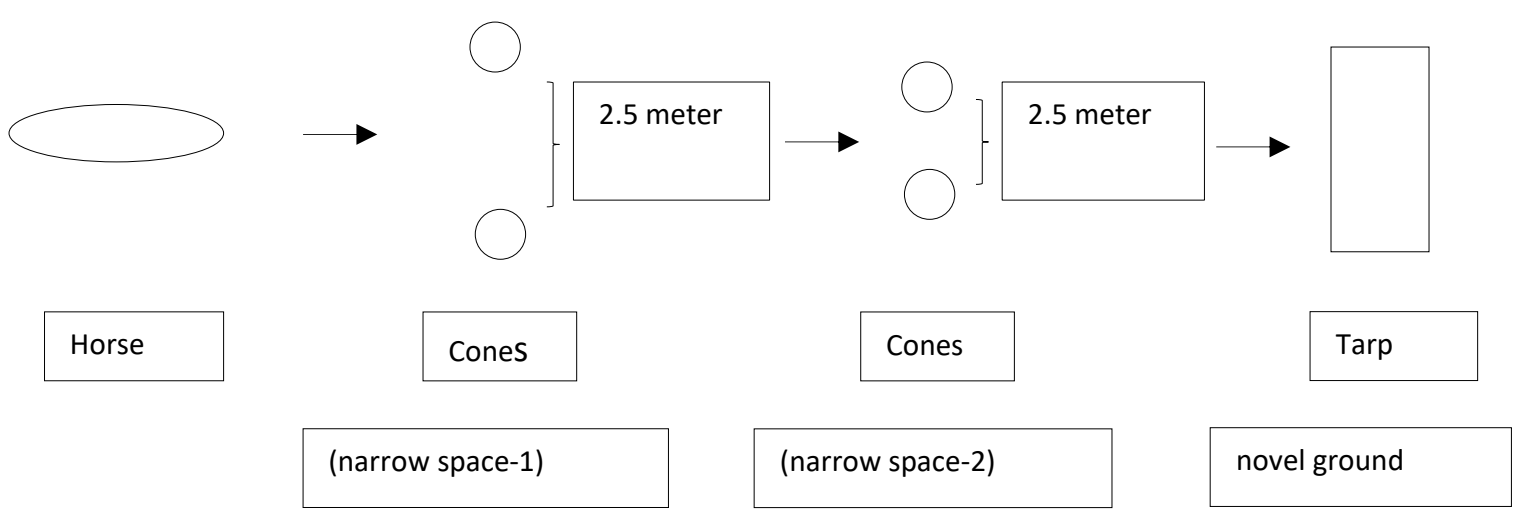

Figure 2. Study design

of the study, is a licensed trainer unfamiliar with the respective horses. For each horse, a training session lasting a maximum of 75 minutes, using three training methods, was carried out in one day. While a horse was training, the other two horses that would be trained that day were kept in the training area to reduce the stress of leaving the herd. All training has its own learning goals. However, for the standardization of the research, regardless of whether the learning goals were reached or not, fixed times were applied. The respective times were measured with the help of a stopwatch. The training methods and combinations applied in each group can be seen in Table 1.

Before and after the application of each training method, horses were directed to pass through a narrowspaces and walk over a tarp (novel/typically frightening tasks) with trainer. The first narrow space was 2.5 meters between two red and white cones of $55 \mathrm{~cm}$ in height. The second was 1.5 meters between cones again. In the task of walking on the tarp, horses were directed to walk on an orange tarp of $70 \times 150 \mathrm{~cm}$ size (Figure 2. Study design). During these tasks, their heart rates (as an indicator of stress), behavioral responses (fright, curiosity, etc.), and their learning responses (the duration of the completion of the task) were examined. In Trainings, the behavior of each horse was assessed by the trainer with the use of video recordings, trainer's notes, and Equid ethograms.

In the study, all three horse training methods were applied to the same horse with all their combinations to test whether these three methods have the potential to complement each other or to increase their effectiveness. Within the scope of the research, Parelli's Seven Games and Join-up methods from conspecific horse training methods and Clicker method within the scope of behavioral horse training were examined. Joinup method used to impose the dominancy of the trainer to the horse and to manipulate its behaviors in a controlled environment (the round pen) (Roberts, 2000; Roberts, 1997). In our study, in Join-up method, the terms of obedience and trust are used instead of "respect," "dominance," and "leadership" because of can jeopardize the welfare of the horse (ISES, 2017). During the research, it was observed and recorded whether the horses were performing one or more of the signs (lowered head, licking-chewing, eye contact, smaller circle) as well as "Join-up" and "Follow-up", which Monty Roberts revealed in the Join-up method. Seven Games developed by Pat Parelli (Friendly Game, Porcupine Game, Driving Game, Yo-yo Game, Circling Game, Sideways Game, Squeeze Game) focuses on enhancing friendship and dominancy relationships between the trainer and the horse (Parelli, 1993). In Parelli method, negative reinforcements are used to make the horse behave in the desired way, and after the desired response is achieved, positive reinforcements are applied. In this research, Friendly and Porcupine Games were applied to horses within the scope of Parelli's Seven Games. Friendly game is designed to persuade the horse that the trainer is a reliable friend. Porcupine game aims at teaching the horse to avoid any pressures applied with fingers. Clicker training is a method in which positive reinforcement is efficiently used in learning theory (Turner, 2013). The unfamiliar sound of the clicker conditions the horse to a reinforcement. The principal reinforcement is food reward (Mills and McDonnell, 2005). In scope of Clicker method, Carrot Stick and Clicker were used. Carrot Stick 
Table 2. Assessment of variables

\begin{tabular}{|c|c|}
\hline Variable & Definition \\
\hline Obedience & The horse walking alongside the trainer without using any pressure on the rope. \\
\hline Disobedience & $\begin{array}{l}\text { The horse dragging the trainer, rearing up, walking too close to the trainer, pushing or pulling } \\
\text { the trainer. }\end{array}$ \\
\hline Trust & $\begin{array}{l}\text { The horse staying calm next to the trainer and does not display frightening behavior towards } \\
\text { any stimulus. }\end{array}$ \\
\hline Fright & $\begin{array}{l}\text { The horse widening of the eyes (the eyes widen, thereby exposing the white around the } \\
\text { pupil), widening of the nostrils (the nostrils widen and exhalation becomes obvious and } \\
\text { louder), and avoidance (walking backward, trying to escape from the trainer, startling from } \\
\text { the trainer's movements) (McLean, 2003, Waring 2003). }\end{array}$ \\
\hline Curiosity & $\begin{array}{l}\text { The horse touching the whip during the Games of Parelli and the target stick in the Clicker } \\
\text { method with their nose, sniffing and looking carefully. }\end{array}$ \\
\hline Precision & The horses do not allow the body parts to be touched. \\
\hline $\begin{array}{l}\text { Positioning the } \\
\text { Horse }\end{array}$ & The horse is positioned in four directions in round pen in the Join-up method. \\
\hline $\begin{array}{l}\text { Conflict } \\
\text { Behaviors }\end{array}$ & $\begin{array}{l}\text { The horse ears laid back, nipping, balking, pushing, head-threat, bite threat, head bumping, } \\
\text { chasing, pawing, kicking, kick-threat. }\end{array}$ \\
\hline Success Rate & $\begin{array}{l}\text { The horse passing through the narrow spaces created within the scope of the research and } \\
\text { being able to walk on a tarp. }\end{array}$ \\
\hline Lack of Attention & $\begin{array}{l}\text { The horse does not respond to the stimuli given by the trainer within the scope of training. } \\
\text { The reaction to the applied effects is reduced or eliminated. }\end{array}$ \\
\hline
\end{tabular}

Table 3. Heart rates in training groups

\begin{tabular}{lllll}
\hline Groups & $\mathrm{N}$ & Minimum & Maximum & Mean $\left(\mathrm{X} \pm \mathrm{S}_{\mathrm{x}}\right)$ \\
\hline 1 & 6 & 40.6 & 201.1 & $79.1 \pm 3.9$ \\
2 & 6 & 43.5 & 186.5 & $78.0 \pm 4.0$ \\
$1+2$ & 12 & 42.0 & 193.8 & $78.5 \pm 2.7$ \\
3 & 6 & 42.0 & 191.5 & $67.0 \pm 3.5$ \\
4 & 6 & 41.3 & 188.8 & $73.6 \pm 3.5$ \\
$3+4$ & 12 & 41.6 & 190.1 & $70.3 \pm 2.7$ \\
5 & 6 & 45.3 & 154.5 & $70.0 \pm 5.3$ \\
6 & 6 & 42.1 & 191.1 & $73.3 \pm 6.5$ \\
$5+6$ & 12 & 43.7 & 172.8 & $71.6 \pm 4.0$ \\
$P$ & & & & - \\
\hline$X \pm S x:$ Arithme
\end{tabular}

XISx: Arithmetic mean and standard error; 1 (J-C-P); 2 (J-P-C); 3 (P-C-J); 4 (P-J-C); 5 (C-P-J); 6 (C-J-P); -: not significant

was approached to the nose of the horse and the word "Target" was used. When the clicker was touched with the nose of the horse, the click was done and the reinforcement (food reward-small pieces of carrot) given to the horse by the trainer within 3 seconds. Then the carrot stick was moved half a meter away from the horse and the word "target" was used. In this research, the aim of the Clicker training is that the horse follows the carrot stick, therefore the trainer willingly.

\section{Statistical Analysis}

Significance tests between the groups in terms of heart rates and training durations were conducted as variance analysis test. Their success in completing the required tasks were checked by chi square test in order to see the impacts of training methods. SPSS 14.0 software (SPSS 2005) was used for statistical analysis.

\section{Assessment of Variables}

The explanations of the variables used in the research are presented in the Table 2. "Assessment of variables" below.

\section{Results}

Heart rate data of training groups can be found in Table 3. Mean heart rates varied from 67.0 to 79.1. As each method was used as the initial method, the number of groups was reduced to three $(1+2,3+4$, $5+6)$, and no significant statistical difference was found among the group in variance analysis (78.5) $(P>0.05)$. The highest mean heart rate was recorded in the groups which started the training with Join up method, and the lowest (70.3) in those who started with the Parelli method. 
The total training duration in each group is demonstrated in Table 4. It can be seen that the longest training duration was in the groups in which Join up method was practiced as the last method (Groups 3 and 5), and the shortest training duration was in those which practiced the Parelli method as the last one (Groups 1 and 6). The differences in training durations among groups are not significant $(P>0.05)$. Examined individually, Join-up and Clicker methods take 15-20 minutes, while the Parelli method takes 3035 minutes to apply.

Table 4. Total training duration (minutes)

\begin{tabular}{lllc}
\hline Groups & Minimum & Maximum & Total $\left(\mathrm{X} \pm \mathrm{S}_{\mathrm{x}}\right)$ \\
\hline 1 & & & \\
2 & 42.3 & 57.8 & $51.9 \pm 2.8$ \\
3 & 39.5 & 71.1 & $57.0 \pm 5.0$ \\
4 & 51.0 & 63.8 & $57.4 \pm 1.7$ \\
5 & 43.6 & 71.5 & $56.2 \pm 4.6$ \\
6 & 50.5 & 67.8 & $61.0 \pm 2.4$ \\
General & 47.6 & 57.1 & $52.0 \pm 1.4$ \\
P & 39.5 & 71.5 & $56.0 \pm 1.3$ \\
& & & - \\
\hline
\end{tabular}

$\mathrm{X} \pm$ Sx: Arithmetic mean and standard error; 1 (J-C-P); 2 (J-P-C); 3 (PC-J); 4 (P-J-C); 5 (C-P-J); 6 (C-J-P); -: not significant

Task completion success rates, obedience, and conflict behaviors of the horses were examined as each method was applied as the first method separately, and according to the sequence of each method in the order or the combination. Therefore, the impacts of Join-up, Parelli, and Clicker methods were examined in terms of learning and behavioral characteristics.
Table 5. demonstrates the task completion success rates of the horses in reference to each training method. Each group of 12 horses starts the training with one of the methods. When these methods are applied by themselves, the success rates in the task of passing through a narrow space are similar, however, those in the task of walking on a tarp vary dramatically (J, 50\%; P, 41\%; C, 75\%). Moreover, single-use of every method resulted in lower success rates than the application of double and triple combinations except the combination in which the Join-up method was applied as the last method (J-C, 83.3\%; J-P, 100\%; P-C, 83.3\%; P-J, 50\%; C-P, 100\%; C-J, 100\%; J-C-P, 100\%; J-PC, 100\%; P-J-C, 66.6\%; C-J-P, 100\%). In the triple combination groups in which the Join-up method was applied as the last method, the success rate in the task of walking on a tarp was the lowest (P-C-J 33.3\%; C-P-J $33.3 \%)$, and the differences among the groups were highly significant $(P<0.01)$. When the Join-up method was applied as the first method in the training, all the horses were more successful in completing the tasks. Combinatory application of methods also increased the success rates, except for the use of the Join-up method as the last part of the training. The highest success rate was the result of triple combinations starting with Joinup methods (100\%), and double combinations starting with the Clicker method (100\%).

Obedience and conflict behaviors with reference to training methods are demonstrated in Table 6. Obedience rates were low and conflict behavior rates

Table 5. Success rates of the horses in completing the tasks with reference to training methods

\begin{tabular}{|c|c|c|c|c|c|c|c|}
\hline \multirow[b]{2}{*}{$\begin{array}{l}\text { Training } \\
\text { Method }\end{array}$} & \multirow[b]{2}{*}{$\mathrm{N}$} & \multicolumn{2}{|c|}{ Narrow Space 1} & \multicolumn{2}{|c|}{ Narrow Space 2} & \multicolumn{2}{|c|}{ Walking on Tarp } \\
\hline & & Number & Rate (\%) & Number & Rate (\%) & Number & $\begin{array}{l}\text { Rate } \\
(\%)\end{array}$ \\
\hline $\mathrm{J}$ & 12 & 11 & 91.6 & 11 & 91.6 & 6 & 50.0 \\
\hline$P$ & 12 & 12 & 100 & 12 & 100 & 5 & 41.6 \\
\hline $\mathrm{C}$ & 12 & 12 & 100 & 12 & 100 & 9 & 75.0 \\
\hline \multicolumn{8}{|l|}{$x^{2}$} \\
\hline $\mathrm{J}-\mathrm{C}$ & 6 & 6 & $\begin{array}{l}- \\
100\end{array}$ & 6 & $\begin{array}{l}- \\
100\end{array}$ & 5 & $\begin{array}{l}- \\
83.3\end{array}$ \\
\hline$J-P$ & 6 & 6 & 100 & 6 & 100 & 6 & 100 \\
\hline \multicolumn{8}{|l|}{$x^{2}$} \\
\hline & & & - & & - & & - \\
\hline P-C & 6 & 6 & 100 & 6 & 100 & 5 & 83.3 \\
\hline P-J & 6 & 6 & 100 & 5 & 83,3 & 3 & 50.0 \\
\hline \multicolumn{8}{|l|}{$x^{2}$} \\
\hline & & & - & & - & & - \\
\hline$C-P$ & 6 & 6 & 100 & 6 & 100 & 6 & 100 \\
\hline C-J & 6 & 6 & 100 & 6 & 100 & 6 & 100 \\
\hline \multicolumn{8}{|l|}{$x^{2}$} \\
\hline & & & - & & - & & - \\
\hline$J-C-P$ & 6 & 6 & 100 & 6 & 100 & 6 & $100^{a}$ \\
\hline$J-P-C$ & 6 & 6 & 100 & 6 & 100 & 6 & $100^{a}$ \\
\hline P-C-J & 6 & 6 & 100 & 5 & 83,3 & 2 & $33.3^{b}$ \\
\hline P-J-C & 6 & 6 & 100 & 6 & 100 & 4 & 66.6 \\
\hline C-P-J & 6 & 3 & 50,0 & 3 & 50,0 & 2 & $33.3^{b}$ \\
\hline C-J-P & 6 & 6 & 100 & 6 & 100 & 6 & $100^{a}$ \\
\hline \multicolumn{8}{|l|}{$x^{2}$} \\
\hline & & & - & & - & & $* *$ \\
\hline
\end{tabular}


were high in the solo use of Join-up method. The use of Parelli method only decreased the conflict behavior rates to minimum, and the use of Clicker method only resulted in the highest rates of obedience. The use of Clicker method the last method in the combination resulted in the obedience of almost all horses. The use of Join-up method as the last method in the combination decreased obedience to minimum and increased conflict behavior rates to maximum. In double combinations, there were statistically significant differences between $\mathrm{P}-\mathrm{C}$ and $\mathrm{P}-\mathrm{J}$ applications $(\mathrm{P}<0.01)$. The differences among triple combinations were also significant $(P<0.01)$. These differences are due to the use of the Join-up method as the last method.

Table 7. includes data on the learning and behavioral characteristics of the horses in the Join-up method. As can be seen in the table, solo and combinatory uses of the Join-up method resulted in high rates of conflict behaviors. Lack of attention was around $50 \%$ in J and CP-J applications, and $16.6 \%$ in other groups. As the lack of attention decreased, the rate of the positioning of the horses increased. While Follow-up rates were generally low in all groups (16.6\%-58.3\%), they were highest in the J group.

Two Parelli games were used in this research: The Friendly Game and the Porcupine Game. Success

Table 6. Obedience and conflict behavior rates with reference to training methods

\begin{tabular}{|c|c|c|c|c|c|}
\hline \multirow[b]{2}{*}{$\begin{array}{l}\text { Training } \\
\text { method }\end{array}$} & \multirow[b]{2}{*}{$\mathrm{N}$} & \multicolumn{2}{|c|}{ Obedience } & \multicolumn{2}{|c|}{ Conflict Behavior } \\
\hline & & Number & Rate (\%) & Number & Rate (\%) \\
\hline $\mathrm{J}$ & 12 & 2 & 16.6 & 8 & 66.7 \\
\hline$P$ & 12 & 6 & 50.0 & 3 & 25.0 \\
\hline $\mathrm{C}$ & 12 & 7 & 58.3 & 4 & 33.3 \\
\hline$x^{2}$ & & & - & & - \\
\hline $\mathrm{J}-\mathrm{C}$ & 6 & 5 & 83.3 & 1 & 16.6 \\
\hline$J-P$ & 6 & 4 & 66.6 & 2 & 33.3 \\
\hline$x^{2}$ & & & - & & - \\
\hline P-C & 6 & 6 & 100 & 0 & 0.0 \\
\hline P-J & 6 & 1 & 16.6 & 5 & 83.3 \\
\hline$x^{2}$ & & & $* *$ & & $* *$ \\
\hline$C-P$ & 6 & 4 & 66.6 & 3 & 50.0 \\
\hline C-J & 6 & 1 & 16.6 & 5 & 83.3 \\
\hline$x^{2}$ & & & - & & - \\
\hline$J-C-P$ & 6 & 5 & $83.3^{\mathrm{a}}$ & 0 & $0.0^{\mathrm{a}}$ \\
\hline J-P-C & 6 & 6 & $100 \underline{a}$ & 2 & $33.3^{\mathrm{b}}$ \\
\hline P-C-J & 6 & 1 & $16.6^{b}$ & 4 & 66.6 \\
\hline P-J-C & 6 & 6 & $100 \underline{a}$ & 0 & $0.0^{\mathrm{a}}$ \\
\hline C-P-J & 6 & 2 & 33.3 & 4 & 66.6 \\
\hline C-J-P & 6 & 5 & $83.3^{a}$ & 0 & $0.0^{\mathrm{a}}$ \\
\hline$x^{2}$ & & & $* *$ & & $* *$ \\
\hline
\end{tabular}

Table 7. Learning and behavioral characteristics in Join-up method (\%)

\begin{tabular}{|c|c|c|c|c|c|c|}
\hline Characteristics & $J \quad(n=12)$ & $\begin{array}{l}\text { P-J } \\
(n=6)\end{array}$ & $\begin{array}{l}C-J \\
(n=6)\end{array}$ & $\begin{array}{l}P-C-J \\
(n=6)\end{array}$ & $\begin{array}{l}\text { C-P-J } \\
(n=6)\end{array}$ & $x^{2}$ \\
\hline The stress of separation from the herd & 91.7 & 83.3 & 83.3 & 83.3 & 66.7 & - \\
\hline Communication with the herd (neigh) & 91.7 & 83.3 & 83.3 & 66.7 & 66.7 & - \\
\hline Disobedience & 83.3 & 83.3 & 83.3 & 83.3 & 66.7 & - \\
\hline Conflict behaviors & 66.7 & 83.3 & 83.3 & 66.7 & 66.7 & - \\
\hline Lack of attention & 58.3 & 16.6 & 16.6 & 16.6 & 50.0 & - \\
\hline Positioning the horse & 33.3 & 83.3 & 50.0 & 66.6 & 33.3 & - \\
\hline Obedience at the end of training & 100 & 66.7 & 50.0 & 100 & 50.0 & - \\
\hline Trust to trainer at the end of the training & 75.0 & 66.7 & 100 & 100 & 33.3 & - \\
\hline Follow-up & 58.3 & 50.0 & 16.6 & 50.0 & 16.6 & - \\
\hline
\end{tabular}

-: non significant 
rates of the horses with the use of this method can be seen in Table 8. The application of the Parelli method in double and triple combinations increased the obedience rates of the horses. In solo application, the success rate was $50 \%$, whereas it was $66.7 \%$ in double and $83.3 \%$ in triple combinations. In the groups Parelli method was applied as the last method of three, all the horses learned vocal cues, trusted their trainers and all the conflict behaviors disappeared. Except for the C-P group, the rates of fright behavior were high and the rates of Precision-2 (to touch its leg) were low. Parelli method results in an increase in obedience rates in double and triple method combinations.

The impact of the Clicker method on the learning and behavioral characteristics of the horses can be seen in Table 9. Almost all the horses demonstrated attention to Carrot Stick. When the Clicker method was applied as the only method and as the last method in combination with others, trust rate was $100 \%$, and all the horses learned the vocal cues. The use of the Clicker method in double and triple combination with other methods resulted in higher obedience rates. With the use of this method, all the horses demonstrated fright, and conflict behaviors decreased dramatically.

\section{Discussion}

Mean heart rates of horses during trainings were high in the groups which started with Join-up method, and low in those which started with Parelli method. Accordingly in our study, when comparing the HR of horses during training, no significant statistical difference was found among the training groups in variance analysis. The increase in heart rate of horses during Join-up training in our study is thought to be caused by physical activity (active beginning of the training), and the stress of separation from the herd due to the fact that the horses have not been separated from the herd before. Lesimple (2020), states that heart rate is an indicator of the welfare of horses. In a study of Loftus et al. (2016), when comparing the HR of horses during Join-up to overall training, there were no significant differences. Similar to our research results, Physick-Sheard et al. (2000) pointed out that the increase in HR may be due to physical exertion and/or an increase in psychological stress. Loftus et al. (2016) stated that the Join-up method, which includes short episodes of canter, may cause an increase in HR due to more physical activity in horses. The findings of the present study are convenient with those of the research conducted by Fureix et al. (2009), which focused on conventional and natural horse breeding methods, and which demonstrated that horses under stress communicate with the herd by neighing. In our study, the use of Join-up method resulted in conflict behaviors more than the use of other methods; and obedience decrease with this method. McGreevy et al. (2005) claim that conflict behaviors are indicators of physical and mental disturbance as a response to treatments during training. At the same time, similar to our research results, they provided that the horse is directed to leave the herd, and to get used to the training field, its stress might be minimized, the success of the method might be increased. Boivin et al. (2003) shows that manipulating the behavior of horses by training them and making them familiar with new conditions will reduce stressrelated behaviors such as neighing, galloping, rearing and defecation, which is consistent with our research results.

Clicker method includes positive reinforcements only. The reason why mean heart rate in Clicker method is higher than in Parelli method is the excitement of the horses to food reward used as the positive reinforcement in Clicker method (Williams et al. 2004). In the groups Parelli method is applied as the last method in combination with others, the application takes less time. As the other methods result in trust and obedience with the trainer, the Parelli method takes the advantage of the application of other methods. Fureix (2009) et al. claim that natural horse breeding practices improve the interaction between the horse and humans. Lansade and Bouissou (2008) state that the amount of contact between the horse and human is in direct correlation with the balancing rate of the responses of the horse.

The success rates in completing the task of passing through narrow space are similar in all methods. However, the rates of success in the task of walking on

Table 8. Data on the rates of learning and behavioral characteristics in the use of Parelli method (\%)

\begin{tabular}{|c|c|c|c|c|c|c|}
\hline Characteristics & $\begin{array}{l}P \\
(n=12)\end{array}$ & $\begin{array}{l}J-P \\
(n=6)\end{array}$ & $\begin{array}{l}\text { C-P } \\
(n=6)\end{array}$ & $\begin{array}{l}J-C-P \\
(n=6)\end{array}$ & $\begin{array}{l}\text { C-J-P } \\
(n=6)\end{array}$ & $x^{2}$ \\
\hline Obedience & 50.0 & 66.7 & 66.7 & 83.3 & 83.3 & - \\
\hline Curiosity in whip & 100 & 83.3 & 100 & 83.3 & 100 & - \\
\hline Fright & 66.7 & 66.7 & 33.3 & 100 & 83.3 & - \\
\hline Conflict behaviors & 25.0 & 33.3 & 50.0 & 0.0 & 0.0 & - \\
\hline Precision-1 (to touch to its head) & 50.0 & 66.7 & 66.7 & 83.3 & 50.0 & - \\
\hline Precision-2 (to touch to its leg) & 8.3 & 16.7 & 66.7 & 16.6 & 16.6 & - \\
\hline Learning vocal cues & 100 & 83.3 & 83.3 & 100 & 100 & - \\
\hline Trust to the trainer at the end of the training & 91.7 & 83.3 & 83.3 & 100 & 100 & - \\
\hline
\end{tabular}


Table 9. The impact of Clicker method on the learning and behavioral characteristics of the horses (\%)

\begin{tabular}{|c|c|c|c|c|c|c|}
\hline Characteristics & $\begin{array}{l}C \\
(n=12)\end{array}$ & $\begin{array}{l}P-C \\
(n=6)\end{array}$ & $\begin{array}{l}J-C \\
(n=6)\end{array}$ & $\begin{array}{l}J-P-C \\
(n=6)\end{array}$ & $\begin{array}{l}P-J-C \\
(n=6)\end{array}$ & $x^{2}$ \\
\hline Obedience & 53.3 & 100 & 83.3 & 100 & 100 & - \\
\hline Curiosity to the stick & 100 & 83.3 & 100 & 100 & 100 & - \\
\hline $\begin{array}{l}\text { Fright (walking backwards and } \\
\text { escaping) }\end{array}$ & 25.0 & 16.6 & 33.3 & 16.6 & 16.6 & - \\
\hline Conflict behaviors & 25.0 & 0.0 & 16.6 & 33.3 & 0.0 & - \\
\hline Learning vocal cues & 100 & 100 & 100 & 100 & 100 & - \\
\hline $\begin{array}{l}\text { Trust to the trainer at the end of the } \\
\text { training }\end{array}$ & 100 & 100 & 100 & 100 & 100 & - \\
\hline
\end{tabular}

-: non significant

a tarp vary dramatically. Christensen et al. (2012) made a research on the learning performances of the horses, and applied Clicker training. Similar to these findings, the present study demonstrated that varying reinforcements increase motivation. Researches by Visser et al. (2003) and Lansade and Simon (2010) resulted in similar findings on the learning performances of horses. Comparing the success rates of the methods, it was found out that $\mathrm{C}>\mathrm{J}>\mathrm{P}$ and Clicker method is 34$55 \%$ more successful than the other methods. The clicker method is recommended if only one method is to be applied. Similarly, Pryor (2002) claims that the Clicker method improves the learning skills of horses in new tasks. Lethbridge (2009) claims that the Clicker method can be used to manipulate horse behaviors during horseshoeing applications. Combinations of two methods generally increase success, and except for the groups in which Join-up is applied as the last method, three methods combined also increase the success. The success of completing the task of walking on a tarp was about 33.3\% in Group 3 and 5, in which Join-up was applied as the last method. The highest success rate in the present study was of the applications of three methods starting either with Join-up or Clicker methods and double combinations starting with Clicker methods. Therefore, it can be concluded that the contents and the sequences of the methods have to be compatible. This finding is compatible with those of the research by Janczarek et al. (2013), in which the researchers claim that horses' responses vary in each method and that this should be taken into consideration in order to guarantee horse welfare.

In terms of obedience, the scores in the solo application of the Clicker method are the highest scores, and those of the Join-up method is the lowest. It should not be forgotten that the most important purpose of round-pen training should be to establish stimulus control in the horse (Fenner et al. 2019). In the combinations of three methods, when the Join-up method was applied as the last one, obedience decreased, and conflict behavior increased dramatically. Similar to our study results, Dai et al. (2019), comparing the loading into a truck time of the horses that using positive reinforcement-based training and without training, it was shown that the training horses had shorter loading time and the clicker training reduced loading stress. Hall and Heleski (2017), define fear as an innate behavioral response that motivates the horse to escape from potential danger. This causes a conflict response to the desired behavior. This finding is similar to the findings of the present study. The Join-up method establishes the hierarchy between the horse and the human, however, when other methods are applied before Join-up, conflict behaviors occur. The application of the Join-up method after other methods in training decreases the stress of separation from the herd to a degree. This is possible with the familiarity and trust other methods may enhance. Communication with the herd and disobedience can be decreased with the combination of methods. Many other types of research also show that the application of learning theory in training gets successful results. Repeated applications of methods decrease stress and increase the success (McGreevy, 2007; McGreevy and McLean, 2007; McGreevy and McLean, 2010).

When Join-up is applied as the only method, Follow-up rates increase. Other methods establish a friendly relationship between the horse and human, however, the Join-up method separates the horse from the herd again. This makes the horse confused and results in difficulties in learning. The application of the Join-up method decreases the rate of positioning, but increase obedience and Followup. For successful training, the Join-up method should be applied by itself, or as the first method in combination with others.

The use of Parelli just after Clicker (C-P) decreases fright. Positive and negative reinforcements without pressure keep the horse calmer. Similarly, Dougherty and Lewis (1992), showed that horses' responses depend on positive reinforcement a great deal. Many other studies emphasize the correlation between positive reinforcement and training horses in new responses (Feng et al. 2016; Flannery, 1997; Sappington and Goldman, 1994; Williams et al. 2004). The findings of the present study are similar to many other experimental types of research (Heird et al. 1986; Lansade et al. 2004; Visser et al. 2002) in that horse training decrease the stress horses are exposed to and improve their emotional responses in facing unfamiliar conditions. The researchers could not explain why the J-C-P combination resulted in anxiety and fright, but it might be suggested that it is due to the individual temperaments of the horses. In their research, Lansade and Simon (2010) showed that the influence of tem- 
perament on learning performance was taskdependent. They found out that temperament did not directly influence learning, but horses develop some dispositions with their responses to stimuli in training. The present study shares the emphasis on the necessity of developing individual programs for each horse and choose an appropriate method for appropriate temperament.

The present study showed that almost all the horses were curious about the target stick. This made the application of the method easier and increased its efficiency due to the horses' willingness to training.

Moreover, fright and conflict behaviors were minimum in this method. Easy application, success in the short term, and minimum danger for the horse and the trainer make the Clicker method an advantageous one. Training systems based on positive reinforcements such as the Clicker method make training processes much easier.

\section{Conclusion}

In the natural behaviors of horses, the hierarchy in the herd is determined initially, and social communication in the limits of this hierarchy occurs then. This process should be taken into consideration while applying methods based on ethology in horse training. This is why the application of the Join-up method before others is successful: It enables the determination of hierarchy between the horse and human. When the Join-up method is followed by the Parelli and Clicker methods, this situation positively affects the success of the training since the communication between horse and human is formed similar to the natural herd dynamics of the horses. In the Join-up method, horse follows the trainer and feels secure with him. After determination of hierarchy, conflict behaviors decrease and horses interact easily. Afterwards, horses can establish friendships, and develop social behaviors such as protecting and grooming each other. Parelli's Games establish friendship, and the trainer can touch the horse's body trustfully. Clicker method uses a very strong positive reinforcement, i.e. feed, as reward. The horse, having developed obedience and become friend with the human, gets ready for cooperation.

In conclusion, as it takes short time and can be applied easily, in solo applications, the Clicker method is the most advantageous one. In triple combinations, Join-up should not be used as the last method, since it takes longer times and decreases success. Join-up is more successful as the first method in combination with others. With this research, it is seen that ordering is important when applying behavioral and conspecific training methods to horses in combinations. It has been revealed that planning the training of horses by considering the dynamics of the herd in their natural life increases the success in training.

\section{References}

Beaver, B.V. (2019). Equine behavioral medicine.65,Academic Press.

Blanchard, S. (2005). The Power of Positive Horse Training. Wiley Publishing.

Boivin, X., Lensink, J., Tallet, C., \& Veissier, I. (2003). Stockmanship and farm animal welfare. Animal Welfare, 12: 479-492.

Christensen, J.W., Ahrendt, L.P., Lintrup, R., Gaillard, C., Palmed, R., \& Malmkvist, J. (2012). Does learning performance in horses relate to fearfulness, baseline stress hormone, and social rank? Applied Animal Behaviour Science, 140: 44- 52. https://doi.org/10.1016/j.applanim.2012.05.003

Czycholl, I., Büttner, K., Klingbell, P., \& Krieter, J. (2018). An indication of reliability of the two level approach of the welfare assessment protocol for horses. Animals, 8: 7. https://doi.org/10.3390/ani8010007

Dai, F., Costa, A.D., Bonfanti, L., Caucci, C., Martino, G.D., Lucarelli, R., Padalino, B., \& Minero, M. (2019). Positive reinforcement-based training for selfloading of meat horses reduces loading time and stress-related behavior. Frontiers in Veterinary Science, 10. https://doi.org/10.3389/fvets.2019.00350

Dalla Costa, E., Dai, F., Lebelt, D., Scholz, P., Barbien, S., Canali, E., Zanella, A.J., \& Minero, M. (2016). Welfare assessment of horses: The AWIN approach. Animal Welfare, 25: 481-488. https://doi.org/10.7120/ 09627286.25.4.481

Dougherty, D.M., \& Lewis, P. (1992). Matching by horses on several concurrent variable- interval schedules. Behavioral Processes, 26: 69-76. https://doi.org/ 10.1016/0376-6357(92)90003-V

Feng, C.F., Howell, T.J., \& Bennett, P.C. (2016). How clicker training works: Comparing reinforcing, marking and bridging hypotheses. Applied Animal Behaviour Science, 181: 34-40. https://doi.org/10.1016/j.applanim. 2016.05.012

Fenner, K., McLean, A., \& McGreevy, P. (2019). Cutting to the chase: How round-pen, lunging and highspeed liberty work may compromise horse welfare. J Vet Behav Clin Appl Res, 29: 88-94, 2019. https://doi.org/10.1016/j.jveb.2018.05.003

Flannery, B. (1997). Relational discrimination learning in horses. Applied Animal Behavior Science, 54: 267$280 . \quad$ https://doi.org/10.1016/S01681591(97)00006-3

Fureix, C., Pagès, M., Bon, R., Lassalle, J.M., Kuntz, P., \& Gonzalez, G. A. (2009). Preliminary study of the effects of handling type on horses' emotional reactivity and the human-horse relationship. Behavioral Processes, 82: 202-210. https://doi.org/10.1016/j.beproc.2009.06.012

Hall, C., \& Heleski, C. (2017). The role of the ethogram in equitation science. Applied Animal Behaviour Science, 190: 102-110. 
ISES (International Society of Equitational Science). (2017). Position statement on the use/misuse of leadership and dominance concepts in horse training. Retrieved May, 10, 2021, from http:// equitationscience.com/equitation /positionstatement-on-the-use-misuse-of-leadership-anddominance-concepts-in-horse-training. 2017.

Janczarek, I., Stachurska, A., Kedzierski, W., \& Wilk, I. (2013). Response of horse of various breeds to a sympathetic training method. Journal of Equine Veterinary Science, 33: 794-801. https://doi.org/10.1016/j.jevs.2012.12.014

Kydd, E., Padalino, B., Henshall, C., \& McGreevy, P. (2017). An analysis of equine round pen training videos posted online: Differences between amateur and professional trainers. PLoS ONE, 12(9): e0184851. https://doi.org/10.1371/journal. pone.0184851

Lansade, L., Bertrand, M.C., Boivin, X., \& Bouissou, M.F. (2004). Effects of handling at weaning on manageability and reactivity of foals. Applied Animal Behavior Science, 87: 131-149. https://doi.org/10.1016/j.applanim.2003.12.011

Lansade, L., \& Bouissou, M.F. (2008). Reactivity to humans: A temperament trait of horses which is stable across time and situations. Applied Animal Behaviour Science, 114: 492-508. https://doi.org/10.1016/j.applanim.2008.04.012

Lansade, L., \& Simon, F. (2010). Horse learning performances are under the influence of several temperemental dimensions. Applied Animal Behaviour Science, 125: 30-37. https://doi.org/10.1016/j.applanim.2010.02.010

Lansade, L., Bonneau, C., Parias, C., \& Biau, S. (2019). Horse's emotional state and rider safety during grooming practices, a field study. Applied Animal Behaviour Science, 217: 43-47. https://doi.org/10.1016/j.applanim.2019.04.017

Lesimple, C. (2020). Indicators of horse welfare: Stateof-the-art. Animals, 10:294. https://doi.org/10.3390/ani10020294

Lethbridge, E. (2009). Knowing your horse: A Guide to Equine Learning, Training and Behavior. Blackwell. London.

Loftus, L., Marks, K., Jones-McVey, R., Gonzales, J.L., \& Fowler, V.L. (2016). Monty Roberts' public demonstrations: Preliminary report on the heart rate and heart rate variability of horses undergoing training during live audience events. Animals, 6 (9):5. https://doi.org/10.3390/ani6090055

McEwen, B.S. (2019). The good side of "stress". The International Journal on the Biology of Stress, 22: 524-525. https:// doi.org/10.1080/10253890.2019.1631794.

McGreevy, P.D. (2007). The advent of equitation science. Veterinary Journal, 174:492-500. https://doi.org/10.1016/j.tvjl.2006.09.008

McGreevy, P.D., \& McLean, A.N. (2007). The roles of learning theory and ethology inequitation. Journal of Veterinary Behavior: Clinical Applications and
Research, 2: https://doi.org/10.1016/j.jveb.2007.05.003

McGreevy, P.D., \& McLean, A.N. (2010). Equitation Science. Wiley-Blackwell, Chichester, UK.

McGreevy, P.D., McLean, A.N., Warren-Smith, A.K., Waran, N., \& Goodwin, D. (2005). Defining the terms and processes associated with equitation. Proceedings of the First International Equitation Science Symposium, pp. 10-43, Melbourne, Australia.

McGreevy, P.D., Oddie, C., Burton, F.L., \& McLean, A.N. (2009). The horse-human dyad: Can we align horse training and handling activities with the equid social ethogram? Veterinary Journal, 181. pp. 1218. https://doi.org/10.1016/j.tvjl.2009.03.005

McLean, A.N. (2003). The Truth About Horses. David \& Charles, Devon, UK.

McLean, A.N, \& Christensen, J.W. (2017). The application of learning theory in horse training. Applied Animal Behaviour Science, 190. https://doi.org/ 10.1016/j.applanim.2017.02.020

Mills, D.S., \& McDonnell, S. (2005). The Domestic Horse. Cambridge University Press.

Parelli, P. (1993). Natural Horsemanship. Western Horseman Colorado Springs. Globe Pequot Press.

Parkin, T., Brown, J., \& Macdonald, E. (2018). Occupational risks of working with horses: A questionnaire survey of equine veterinary surgeons. Equine Veterinary Education, 30, 200205. https://doi.org/10.1111/eve.12891

Physick-Sheard, P.W., Marlin, D.J., Thornhill, R., \& Schroter, R.C. (2000). Frequency domain analysis of heart rate variability in horses at rest and during exercise. Equine Veterinary Journal, 32, 253-262. https://doi.org/10.2746/042516400776563572

Pryor, K. (2002). Don't Shoot The Dog The New Art of Teaching and Training, Bentam Books, New York.

Roberts, M. (1997). The Man Who Listens to Horses. Arrow Books. London.

Roberts, M. (2000). Join-Up: Horse Sense for People. Harper Collins. London.

Sappington, B.F., \& Goldman, L. (1994). Discrimination learning and concept formation in the Arabian horse. Journal of Animal Science, 12: 3080-3087. https://doi.org/10.2527/1994.72123080x

SPSS 14. (2005). Statistical package for the social sciences. (Licence number: 9869264).

Turner, O. (2013). Exploring clicker training: A method of positive reinforcement to improve the welfare of horse training. Conference Proceedings of the 9th International Equitation Science Conference, pp. 56, USA.

Visser, E.K., Van Reenen, C.G., Van, Der Werf, J.T.N., Schilder, M.B.H., Knaap, J.H., Barneveld, A., \& Blokhuis, H.J. (2002). Heart rate and heart rate variability during a novel object test and a handling test in young horses. Physiology and Behavior, 76: 289-296. https://doi.org/10.1016/S00319384(02)00698-4 
Visser, E.K., Van Reenen, C.G., Schilder, M.B.H., Barneveld, A., \& Blokhuis, H.J. (2003). Learning performance in young horses using two different learning tests. Applied Animal Behavior Science, 80:311-326. https://doi.org/ 10.1016/S01681591(02)00235-6

Waran, N., McGreevy, P.D., \& Casey, R.A. (2007). Training methods and horse welfare. Animal Welfare, 1: 151180.

Waran, N., \&Randle, H. (2017). What we can measure, we can manage: The importance of using robust welfare indicators in Equitation Science, Applied Animal Behaviour Science, 190: 74-81. https://doi.org /10.1016/j.applanim.2017.02.016

Waring, G., 2003. Horse behavior, 2nd ed. Noyes Publications/William Andrew Publishing, Norwich, NY.
Williams, J.L., Friend, T.H., Nevill, C.H., \& Archer, G. (2004). The efficacy of a secondary reinforcer (clicker) during acquisition and extinction of an operant task in horses. Applied Animal Behaviour Science, 88:331-341. https://doi.org/10.1016/j.applanim.2004.03.008

Witkowska-Piłaszewicz, O., Grzędzicka, J., Sen, J., Czopowicz, M., Zmigrodzka, M., Winnicka, A., Cywinska, A., \& Carter, C. (2021). Stress response after race and endurance training sessions and competitions in Arabian horses. Preventive Veterinary Medicine. https://doi.org/10.1016/j.prevetmed.2021.1052 65 